\title{
Probabilistic Sea Level Rise Flood Projections Using a Localized Ocean Reference Surface
}

Noah A. Paoa-Kannegiesser ( $\nabla$ npaoakan@hawaii.edu )

University of Hawai囚i at Mānoa

Charles H. Fletcher

University of Hawaiđi at Mānoa

Tiffany R. Anderson

University of Hawaiði at Mānoa

Makena Coffman

University of Hawaiði at Mānoa

\section{Research Article}

Keywords: Probabilistic Sea, distinguishing flooding, flood probabilities

Posted Date: January 3rd, 2022

DOI: https://doi.org/10.21203/rs.3.rs-1201271/v1

License: (c) (i) This work is licensed under a Creative Commons Attribution 4.0 International License.

Read Full License 


\section{Abstract}

Projecting sea level rise (SLR) impacts requires defining ocean surface variability as a source of uncertainty. We analyze data from a Regional Ocean Modeling System (ROMS) reanalysis for the region surrounding the main Hawaiian Islands to incorporate the ocean surface uncertainty in mapping SLR flood probabilities. By analyzing the ocean surface height component of the ROMS reanalysis, we create an ocean surface reference (ORS) as a proxy for MHHW. We model the NOAA Intermediate, Intermediatehigh and High regional SLR scenarios for the years 2050 and 2100 at three field sites around O\ahu; Waikīkī, Hau囚ula, Hale囚iwa. We calculate a probability density function (PDF) by convolving the PDF of water level derived from the ROMS reanalysis data with the PDF of error associated with a digital elevation model of the study sites. The resulting joint-PDF of flood depth allows us to create two types of probability-based flood projections: (1) Maps illustrating varying flood depths for a given probability threshold and, (2) maps illustrating varying probability for a specific flood depth. We compare $80 \%$ probability flood projections using our ORS approach to projections using the TCARI grid, the standard NOAA method. We highlight the importance of uncertainty and user-defined probability in identifying pixels that function as tipping points distinguishing flooding styles.

\section{Introduction}

Acceleration of global mean sea level rise (GMSLR) is likely to increase with continued global warming ${ }^{1,2}$. Global mean sea level is projected to rise 0.44-0.76 m (SSP2-4.5) to 0.63-1.01 m (SSP5-8.5) by the end of the century ${ }^{3}$. However, a rise approaching $2 \mathrm{~m}$ by 2100 and $5 \mathrm{~m}$ by 2150 cannot be ruled out, as there remains deep uncertainty regarding ice sheet processes ${ }^{3}$. Recent findings by Weber et al. ${ }^{4}$ suggest that accelerating mass loss from the West Antarctic ice sheet may mark the start of a retreat period that will contribute to substantial global sea level rise (SLR) for centuries to millennia. Concerns that IPCC modeling focus on the low end of possible outcomes ${ }^{5}$, thus detracting attention from plausible high-end impacts, are consistent with the findings of Aschwanden et al. ${ }^{6}$ in the case of Greenland, and DeConto et al. $^{7}$ in the case of West Antarctica. Observations ${ }^{8}$ show accelerating ice discharge in the Amundsen Sea sector, lending further credence to concerns about multi-meter SLR this century ${ }^{9}$. Given key uncertainties in ice sheet mass loss ${ }^{10,11}$ and long-term responses to warming ${ }^{12}$, this issue continues to motivate coastal communities to engage in planning for unique and demanding scenarios for which few professionals have formal training ${ }^{13,14}$.

The local expression of SLR can differ significantly from GMSLR ${ }^{15,16,17}$. In addition to vertical land motion and spatially varying patterns of ocean heat storage, gravitational effects related to mass loss ${ }^{18}$ produce unique local and regional sea level deviations ${ }^{19,20,21}$. Additionally, present day 100-yr extreme sea level events are projected to occur at least once a year by the end of the century, even under only $1.5^{\circ} \mathrm{C}$ of warming ${ }^{22}$. Because no single physical model accurately represents all major processes contributing to SLR, Sweet et al. ${ }^{23}$ developed both global mean and local relative scenarios out to the year 2100 that frame risk tolerance for use by planners. However, their Low and Intermediate-low 
scenarios are already exceeded by the observed acceleration of GMSLR $(0.65 \pm 0.12 \mathrm{~m})^{1}$. Thus Sweet et al.'s ${ }^{23}$ Intermediate, Intermediate-High, and High relative sea level rise (RSLR) values represent more realistic scenarios for modeling impacts.

Low-lying elevation areas in Hawaiði already flood during extreme tides and are projected to worsen over the next decade ${ }^{24,25}$. High water levels develop for multiple reasons, such as when eddy-like anomalies are coincident with high background sea levels ${ }^{26}$. Under these conditions, there is greater exposure to seasonal wave inundation ${ }^{27}$, coastal erosion ${ }^{28}$, groundwater inundation ${ }^{29}$, and drainage system blockage $\mathrm{e}^{30}$.

The most intuitive consequence of SLR is that coastal areas will flood when ocean water travels inland across low elevation lands or through existing waterways (i.e., hydrologically connected to the ocean) ${ }^{31}$. So-called "bathtub" modeling using digital elevation models (DEMs) is the most common method of depicting flood exposure. This type of modeling neglects dynamic oceanographic processes and therefore it has been referred to by various authors as "passive"32, "hydrostatic"33, "planar"34, "equilibrium" 35 and "static" 36 .

Projections of flood probability due to SLR require an assessment of elevation uncertainty related to the tidal surface as well as the flooded terrain ${ }^{37}$. In the continental U.S., NOAA uses VDatum ${ }^{38}$ to estimate tidal surface uncertainty (a numerical product representing the difference between modeled and observed water levels). Alaska and U.S. affiliated islands, including Hawai囚i, use the Tidal Constituent and Residual Interpolation method (TCARI) ${ }^{39}$. The TCARI method estimates tidal uncertainty using the difference between an interpolated surface generated from tidal constants, local datums and residual water levels, and tide station observations.

Here we present a new method to quantify water level variability in the ocean surface elevation using modeled water surfaces produced by the Regional Ocean Modeling System (ROMS; www.myroms.org) ${ }^{40}$. We compare our results to the TCARI method at three locations on the island of OVahu (Figure 1). The Pacific Islands Ocean Observing System (PaclOOS; https://pacioos.org/) has produced a reanalysis of oceanographic conditions including water level variability around the Hawaiian Islands ${ }^{41}$. The PaclOOS reanalysis assimilates all available oceanographic observations over the 10-year period 2007-2017. We use this product, here named an ocean reference surface (ORS), as a source of virtual tidal stations (individual pixels near the coast) with which we define tidal uncertainty for the waters around Oखahu. We validate this methodology using tide stations in the NOAA network.

We produce probability density functions (PDFs) for the modeled daily high-water levels and the DEM uncertainty to develop probabilistic estimates of flood-depth under scenarios of SLR. Our products are depicted in the form of geographic information systems (GIS) map layers that can be posted to a public website for use by government and other stakeholders in developing adaptation plans. 


\section{Methods}

We model RSLR exposure on O『ahu under the Intermediate, Intermediate-high, and High scenarios of Sweet et al. ${ }^{23}$ for the years 2050 and 2100 . Hydrologically connected locations exposed to marine overland flow, and topographically isolated locations vulnerable to groundwater inundation ${ }^{43}$, are depicted relative to an ORS that is a proxy for Mean Higher High Water (MHHW). We convolve a distribution of the daily highest water level provided by the PaclOOS ROMS reanalysis, with a Gaussian distribution of terrain elevation based on the DEM elevation and associated errors, to produce a flooddepth probability distribution. The convolution is solved numerically for each pixel using python 3.5. The result is a PDF of flood-depth for each pixel of the DEM. This allows us to produce two types of probability-based flood maps, one that shows the range of depths at a fixed probability of flooding, and one that shows the range of probabilities at a fixed flood-depth. Each step of our methodology is described in more detail below.

Ocean Reference Surface (ORS). To define an ORS that is a proxy for MHHW, we analyze a 10-year ocean reanalysis for the region surrounding the main Hawaiian Islands ${ }^{41}$ available from the Pacific Islands Ocean Observing System (PaclOOS; https://pacioos.org/). The reanalysis was performed by Powell et al. ${ }^{41}$ using ROMS v3.6 with a 4-D variational data assimilation that included sea surface temperature, salinity, height anomalies, surface velocity, and depth profiles of temperature and salinity. The output consists of 3-hourly data, at a spatial resolution of approximately $4 \mathrm{~km}$.

To validate our approach, we analyzed the ROMS ocean surface height component for the location closest to the Honolulu Tidal Station (NOAA \#1612340) and compared it to the Honolulu tide station data $^{44}$. To match the datum of the DEM, we normalize each pixel's reanalysis data to mean sea level (MSL) by subtracting every surface height value from an average of the entire dataset. Since we are interested in identifying flood under mean higher high tide conditions, we scanned the ROMS reanalysis data for daily highest sea level using a 24-hour window and did the same for the tidal station data over the same period (2007-2017) and at the same sampling interval (3hr) as the ROMS reanalysis. It is important to note that this time frame differs from the NOAA tidal epoch (1983-2001).

Digital Elevation Model (DEM). A DEM representing the topographic elevation of the local terrain is provided by the NOAA Digital Coast program (https://coast.noaa.gov/slrdata). Elevation data was derived from multiple LiDAR (Light Detection and Ranging) measurements collected on the island of O囚ahu in 2013 by the Joint Airborne Lidar Bathymetry Technical Center of Expertise. The DEM is a hydro-flattened, bare-earth product referenced to local MSL with a horizontal resolution of $3 \mathrm{~m}$ and a vegetated vertical accuracy (VVA) of $0.268 \mathrm{~m}$ (Digital Coast Metadata). The value of the VVA is greater than the vertical accuracy value of the bare-earth DEM. We use VVA as the uncertainty (standard deviation) in DEM elevations, in conformity with the NOAA Sea Level Rise Viewer methodology, to obtain more conservative results. 
Hydrologically Connected vs Topographically Isolated. Following the methods in Anderson et al. ${ }^{32}$, we assume that the groundwater level near the coast is equal to predicted tidal heights. Modeling by Habel et al. ${ }^{43}$ confirms that groundwater level at high tide in Honolulu can be represented by the passive MHHW surface. In depicting flooding related to RSLR, we use the ORS as a proxy for MHHW and define flooded areas as those that probabilistically fall below our reference surface. We then label pixels as either: (1) hydrologically connected to the ocean, or (2) topographically isolated (no hydrologic connection to the ocean) under the assumption that topographically isolated flooded pixels are potentially flooded by groundwater inundation.

RSLR Scenario Mapping. Sweet et al. ${ }^{23}$ provide sea level rise scenarios used by planners according to risk. They corrected each scenario to reflect the changing influences of gravity, earth spin, and vertical land motion at the network of U.S. tide stations ${ }^{23}$. Decadal values of SLR, provide a temporal framework for each scenario. To simulate a rise in sea level, we: 1) create a PDF of future daily high water levels by adding the desired SLR increment to the PDF of the current daily higher high water levels as defined in the ORS, then; 2) we create a PDF of terrain elevation at each DEM pixel as a gaussian distribution where the mean is the DEM elevation and the standard deviation is the VVA of the DEM, next; 3 ) we calculate the PDF of flood depth at each pixel by numerically convolving the PDF of water level with the PDF of the DEM multiplied by (-1). Note: the PDF of the sum of two independent random variables is the convolution of the two individual PDFs. Thus, PDF (water level - DEM) = CONV [PDF (water level), PDF (-DEM)]. From this we derive a cumulative density function (CDF) to make two types of maps; a map of flood-depth at a specified probability level, and, a map of the probability of exceeding a specific flood-depth (Figure 2).

To summarize the difference in the amount of flooded area between TCARI and ROMS methodologies, we calculated the percent difference of flooded pixels while distinguishing between flooding styles (hydrologically connected vs topographically isolated). Note: percent difference $=(T C A R I$ area - ROMS area)/((TCARI area + ROMS area)/2). This was done for each study site and for all NOAA RSLR scenarios. Finally, we averaged percentages for each flooding style across the study sites for 2050 and 2100.

Probability of Flood-depth (Figure 2a). Maps that depict flood-depth range at a specific probability under an assumed RSLR scenario ( $1.19 \mathrm{~m}$ by 2100 , Intermediate scenario ${ }^{23}$ ), are built using chosen probability values (e.g., 20\%, 80\%, 90\%) and matching depths from the CDF of each pixel. Maps are color coded to highlight $0.3 \mathrm{~m}$ depth increments for the given RSLR scenario, as well as to identify hydrologically connected vs. topographically isolated pixels. These provide depictions of flood-depths for a given probability at a given sea level rise, that are useful for engineering and architectural project design.

Probability of Flooding (Figure 2b). Maps that depict the probability of flooding under a given sea level rise flood depth, are similarly derived using the CDF of individual pixels. Here, color coding reveals probability rather than depth. The entire map depicts the probability of any flooding at all under a fixed amount of sea level rise, in this case $1.19 \mathrm{~m}$ by 2100 (Intermediate scenario ${ }^{23}$ ). These maps are also 
useful for engineering and architectural projects, especially where the probability of a specific flood-depth is a critical design parameter, such as in transportation planning ${ }^{45}$.

\section{Results}

Following, we discuss the results of validating the ROMS water level distribution, comparisons of TCARI and ROMS flooding, and construction of flood probability maps. We simulated RSLR flooding in 2050 and 2100 for three areas on the island of O囚ahu: 1) Waikīkī (south shore), 2) Hau囚ula (east shore), 3) Hale冈iwa (north shore), using Intermediate, Intermediate-High and High scenarios provided by Sweet et al. ${ }^{23}$ for the Honolulu tide station. For each area, we produced flood maps illustrating daily higher high water flooding at least $80 \%$ probability for a given scenario using TCARI and ROMS methods. We average differences in the flooded-pixel count for each method as well as for the specific cases of hydrologically connected and topographically isolated locations (Table 1). Figure 3 illustrates these differences in the case of the Waikīī study area. Lastly, we present the results of developing probability maps for our three study areas using the ROMS method.

Validation of daily high-water distribution. PaclOOS serves the ROMS reanalysis dataset as a regional pixel network with $4 \mathrm{~km}$ resolution. We treat the pixel closest to the Honolulu tidal station as a virtual tide gauge and derive a MHHW proxy of $0.296 \pm 0.115 \mathrm{~m}$ above MSL. As a validation step, we subsample Honolulu tide station observations to exactly match the ROMS reanalysis timeframe and derived a value of $0.304 \pm 0.108 \mathrm{~m}$ above MSL. A visual comparison of the distributions of daily higher high water from the NOAA tidal station and the ROMS reanalysis is provided in Figure 4.

TCARI vs ROMS probability mapping. As RSLR increases, the land area that shows at least an $80 \%$ probability of flooding extends inland from the shoreline and overflows waterway embankments. Flooding in topographically isolated areas expands and quickly joins with widening areas of marine flooding. Averaging the flooded-pixel count in all three study sites under all NOAA scenarios using the ROMS method reveals that flooding expands from 1.5\% of the total mapped area in 2050 to $37.7 \%$ by the end of the century. The TCARI method yields similar results with flooded areas expanding from 1.73$39.6 \%$ between 2050 and 2100 . However, there are differences in flood extent and style when comparing the two methods. In general, the TCARI method projects greater flooding than the ROMS method. Areas of difference, typically due to greater TCARI flooding, tend to surround areas of agreement (as a "fringe" that expands flooding).

The style of flooding will vary depending on the terrain and the amount of RSLR. For instance, in the Waikīī study area, with a RSLR of $0.75 \mathrm{~m}$ by 2050 (NOAA High scenario), projected flooding is largely confined to topographically isolated locations, and is not the result of overland marine flow. However, by 2100 , under the NOAA Intermediate scenario $(1.19 \mathrm{~m})$, the situation changes and hydrologically connected, and topographically isolated areas display similar amounts of flooding (Figure 3 ). Under Intermediate-High and High scenarios, hydrologically connected inundation is dominant. 
Table 1

Average across all study sites of percent difference in flood area between the ROMS and TCARI approaches, for three NOAA regional sea level scenarios (Honolulu tide station), in the years 2050 and 2100.

\begin{tabular}{|c|c|c|c|c|c|c|c|}
\hline \multirow{2}{*}{$\begin{array}{l}\text { RSLR } \\
\text { Scenarios }\end{array}$} & \multicolumn{3}{|l|}{2050} & \multirow{2}{*}{$\begin{array}{l}\text { RSLR } \\
\text { Scenarios }\end{array}$} & \multicolumn{3}{|l|}{2100} \\
\hline & $\begin{array}{l}\text { hydro } \\
\text { connected }\end{array}$ & $\begin{array}{l}\text { topo } \\
\text { isolated }\end{array}$ & total & & $\begin{array}{l}\text { hydro } \\
\text { connected }\end{array}$ & $\begin{array}{l}\text { topo } \\
\text { isolated }\end{array}$ & total \\
\hline $\begin{array}{l}\text { Intermediate } \\
(40 \mathrm{~cm})\end{array}$ & $28.35 \%$ & $51.26 \%$ & $28.24 \%$ & $\begin{array}{l}\text { Intermediate } \\
(119 \mathrm{~cm})\end{array}$ & $17.93 \%$ & $20.66 \%$ & $19.15 \%$ \\
\hline $\begin{array}{l}\text { Intermediate } \\
\text { High (57 cm) }\end{array}$ & $5.84 \%$ & $21.59 \%$ & $10.94 \%$ & $\begin{array}{l}\text { Intermediate } \\
\text { High (193 } \\
\text { cm) }\end{array}$ & $5.77 \%$ & $19.21 \%$ & $6.03 \%$ \\
\hline High $(75 \mathrm{~cm})$ & $17.81 \%$ & $19.67 \%$ & $17.97 \%$ & $\begin{array}{l}\text { High }(270 \\
\mathrm{cm})\end{array}$ & $2.96 \%$ & $14.17 \%$ & $2.49 \%$ \\
\hline
\end{tabular}

TCARI vs. ROMS flood area difference. Table 1 compares TCARI and ROMS flood projections. Expressed as a percent difference in flood area, we find significant disagreement in both total flood area, as well as the type of flooding (hydrologically connected vs. topographically isolated). The largest disagreement in total flood area is found in the Intermediate scenario where the two methods differ by $28.24 \%$ in 2050 and $19.15 \%$ in 2100 . It is notable that in 2050 there is a $51.26 \%$ difference under the Intermediate scenario for flooding at topographically isolated locations. Strong agreement is found however, in projecting the flooding of hydrologically connected areas under the Intermediate-High scenario for 2050 $(5.84 \%)$ and for 2100 (5.77\%). Overall, the strongest agreement in flood projections is found under the High scenario in 2100 where the two methods differ by only $2.96 \%$ for hydrologically connected areas and $2.49 \%$ in total flood area.

\section{Discussion}

Using a ROMS reanalysis containing ocean level variability data, we define a reference surface that serves as a valid proxy for MHHW. We apply this proxy in producing SLR flood probability maps distinguishing direct marine overland flow from topographically isolated flooding. Our results show that when comparing our model products with flood maps produced using the TCARI method, significant differences are found under NOAA RSLR scenarios for 2050 and 2100. The flood maps reveal several features that are critical to appropriate interpretation and application of these products. These are discussed below.

Disagreement. Analyzing the TCARI and ORS model products highlights a difference pattern in the form of a "fringe" surrounding flood projections where the two methods otherwise agree. We find that the fringe zone is typically a TCARI product. That is, the ROMS method in general projects less flooding than the TCARI method. 
As shown in Figure 4, this disagreement reflects a difference in the shape and location of the probability distributions of the ORS and TCARI products. The TCARI tidal distribution has a tighter spread and it is shifted right compared to the ROMS distribution. This shift represents a departure from the NOAA tide station observations of water level variability and creates an increase of at least $0.03 \mathrm{~m}$ in mean flood height. As a result, the TCARI method projects increased flooding compared to the ORS method. Figure 4 also reveals that the daily high-water values near the mean occur more often in the TCARI distribution than in the ROMS and NOAA distributions and consequently a tighter CDF after the convolution.

Figure 5 illustrates how the spread of the CDF will determine the inundation probability value for a given pixel. When selecting the value that corresponds to any flooding at all ( $>0 \mathrm{~m}$ flood-depth) the probability will be lower when the spread is larger (Note: $(a)=1-0.27=0.73<(b)=1-0.18=0.82$ ). Thus, if we were to map flooding with a probability of at least $80 \%$, CDF (a) would select the hypothetical pixel shown in Figure 5. Whereas CDF (b) would not, and would therefore generate a fringe.

Figure 4. Probability density functions of daily highest high-water variability as obtained from the NOAA tide station in Honolulu Harbor, the ROMS Reanalysis, and a normal distribution of the mean of daily higher high water from the TCARI tidal surface. Vertical lines correspond to the mean of the respective distributions.

Figure 5. Comparison of two CDFs with the same mean but different flood depth spread. The figure illustrates how a broader spread results in a lower probability for corresponding flood depths.

Flood Patterns. The distinction between marine overland flooding and groundwater flooding hinges on whether a flooded area is directly connected to the ocean. The difference may be determined by a single pixel that allows for a region identified by ROMS as topographically isolated, to be mapped by the TCARI method as flooded by marine overland flow. Given the difference in the probability distributions of the TCARI and ROMS data, there is significant opportunity for this to occur. Single pixels or a small group of pixels can connect otherwise isolated areas and may serve as tipping points or flood pathways that open areas to flooding by marine overland flow. The differences that result may actually be physically meaningless as these low-lying inland areas will likely flood anyway, if not by marine overland flow, then by groundwater inundation.

Roads. Roads may be flood conduits or barriers to flooding depending on engineering style. This needs to be recognized when considering adaptation plans. On one hand, when roads are located near the shoreline at low elevations, they may function as waterways. A good example of this is shown in Figure 3 where roads that branch out from the Ala Wai Canal are seen to channelize marine overland flow and promote flooding farther inland. In addition, low elevation roads may connect low-lying areas that might otherwise not experience direct marine flooding. On the other hand, raised embanked roads prevent overland flow, potentially creating areas of topographically isolated stagnant water. Additionally, they could interfere or eliminate tide and wave driven circulation that would eventually become important in maintaining water quality given the essentially permanent nature of sea level rise ${ }^{3}$. Embankments may 
also direct flooding to otherwise dry land parcels. It is important to note that topographic barriers to direct marine flooding such as embanked roads, sea walls, and other structures fail to prevent storm drain backflow and groundwater inundation. As such, models that depict the impacts of sea level rise must include all relevant flood sources ${ }^{30}$.

Topographically isolated locations. Topographically low-lying areas may be flooded by groundwater inundation or storm drain backflow. These areas need to be clearly identified in flood projections in order for engineers and planners to find solutions to groundwater-flooding-specific adaptations and design resilient future communities.

King tides. The hydrostatic projections presented in this study do not include dynamic ocean processes such as wave overtopping, coastal erosion, or other physical oceanographic processes. However, they are useful for visualization of extreme tide impacts. For instance, Thompson et al. ${ }^{25}$ projects that by midcentury, coastal sites will see a dramatic increase in king tide frequency. Additionally, under the NOAA Intermediate scenario, global mean sea level is projected to reach $0.3 \mathrm{~m}$ by $2050^{23}$. A hydrostatic map depicting $0.6 \mathrm{~m}$ of flooding is useful for illustrating a $0.3 \mathrm{~m}$ king tide on top of the $0.3 \mathrm{~m}$ SLR projection.

Probability-based maps. Flood-depth and probability can both be used as thresholds depending on the user's objective and the situation that is being analyzed. Some scientists tend to prefer probability values that correspond to standard deviations in a normal distribution (e.x., 68\%, 95\%, 99.7\%). Similar values were used by Mastrandea et al. ${ }^{46}$ when developing the IPCC AR5 likelihood scale. Other professional fields might prefer different values as thresholds when determining risk, exposure, vulnerability, and other criteria. For instance, NOAA uses $20 \%$ and $80 \%$ as the confidence bounds of their flood mapping methodology ${ }^{47}$. However, the NOAA Sea Level Rise viewer main maps do not make the level of confidence immediately visible. In addition, the flooded areas are displayed with blue shades but there is no flood-depth value associated with the colors. Although there is uncertainty associated with this type of mapping, the lack of flood-depth values leaves users, especially the ones with publicly facing adaptation projects, with poor understanding of potential damage related to flood depth. For instance, a $15 \mathrm{~cm}$ flood, which can be associated with a king tide event, would be a critical threshold for transportation engineering as it is considered likely to stall small vehicles ${ }^{48}$. However, a $15 \mathrm{~cm}$ temporary flood in open spaces or recreational areas might not be a reason to trigger expensive and disruptive adaptation efforts.

Probability of flooding and flood depth values are essential to provide map users with a perspective of the severity of the flooding. User-defined probabilistic flood maps have the potential to open a new world of adaptation efforts. Therefore, although it may prove difficult to implement, interactive websites that allow users to access GIS layers by choosing probability or flood-depth values should be developed. This is especially enticing given that similar information is already available (e.g., NOAA SLR Viewer, PaclOOS SLR Viewer), it just needs to be reconfigured in a user-friendly form.

\section{Conclusion}


In this study we have introduced a new methodology for generating flood maps. We use data from a Regional Ocean Modeling System (ROMS) reanalysis to add the uncertainty of ocean surface height to the uncertainty related to the DEM of the terrain. We use this approach to model three NOAA RSLR scenarios $^{23}$. We selected a probability value of $80 \%$ to match that of the NOAA Sea Level Rise Confidence Mapping to analyze the differences between the two methodologies.

We found that there are significant differences between the results of the two mapping methodologies, which arise due to the location and shape of the TCARI sea level distribution. We have found that generally the use of ROMS reanalysis data tend to generate a smaller footprint than the TCARI method. The use of ROMS allows us to account for the uncertainty of a tidal surface utilizing the distribution of daily higher high water. As seen in Figure 4, the distributions of daily higher high water (both from the NOAA tidal station and ROMS) are not normal, therefore it is a more realistic representation of daily water variability than a distribution of the mean (TCARI).

Visualizing differences between the ROMS and TCARI methods reveals the importance of single pixels (or groups of pixels) that create a direct connection to the ocean in otherwise topographically isolated areas. Distinguishing between the flood styles is crucial as it will dictate the most appropriate adaptation measures to create a resilient community.

The probability value chosen to project flooding may play a crucial role in adaptation decisions. Probability values not only change the extent of flooding but also dictate when areas will be categorized as topographically isolated or hydrologically connected. Because of this, it is important to provide a user with a choice of probability values and flood-depth thresholds that are most meaningful to their goals. Internet map servers depicting flood exposure should be reconfigured to provide a range of user-defined values in order to optimize SLR adaptation and management decisions.

The range of probability values provided through our method can be assigned as standards to specific types of assets based on their economic value, social role, or other criteria. For assets of greater value that when flooded impose a larger impact on a community, decision makers should prefer a smaller probability value. Although it might be counter intuitive, a smaller probability value will result in a larger area of projected inundation and therefore a more conservative approach to policy development and decision-making. Put in perspective, areas of at least $80 \%$ probability of flooding are surrounded by areas of at least $20 \%$ probability of staying dry. Whereas areas of at least $20 \%$ probability of flooding area surrounded by areas of at least $80 \%$ probability of staying dry.

This study shows that ROMS reanalysis data may be used for projecting SLR flood extent. Other coastal communities can make use of ROMS reanalysis data in areas with sparse tidal observation and when VDatum is not available.

\section{Declarations}

Data Availability 
The data used in this study is available from the groups in the text or in citations. Other intermediate products are available upon request to npaoakan@hawaii.edu.

\section{Acknowledgements}

We thank Harold KL Castle Foundation, U.S. Office of Naval Research, City and County of Honolulu, the National Oceanic and Atmospheric Administration and Hawai囚i Community Foundation.

\section{Author contributions}

N.A.P. and C.H.F. wrote the main manuscript text. N.A.P. prepared figs 2,3,4 and 5. T.A. developed original convolution script and assisted with data analysis. N.A.P. adapted convolution script for python. developed automation script and performed the bathtub model. All authors discussed the results and reviewed the manuscript.

\section{Competing Interests}

The authors declare no competing interests.

\section{References}

1. Nerem, R. S. et al. Climate-change-driven accelerated sea-level rise detected in the Altimeter Era. Proceedings of the National Academy of Sciences 115, 2022-2025 (2018).

2. Dangendorf, S. et al. Persistent acceleration in global sea-level rise since the 1960s. Nature Climate Change 9, 705-710 (2019).

3. Masson-Delmotte, V. et al. Climate change 2021: The physical science basis. Contrib. Work. Group Sixth Assess. Rep. Intergov. Panel Clim. Change, (2021)

4. Weber, M. E., Golledge, N. R., Fogwill, C. J., Turney, C. S. \& Thomas, Z. A. Decadal-scale onset and termination of Antarctic ice-mass loss during the last deglaciation. Nature Communications 12, (2021).

5. Siegert, M., Alley, R. B., Rignot, E., Englander, J. \& Corell, R. Twenty-first century sea-level rise could exceed IPCC projections for strong-warming futures. One Earth 3, 691-703 (2020).

6. Aschwanden, A., Bartholomaus, T. C., Brinkerhoff, D. J. \& Truffer, M. Brief communication: A roadmap towards credible projections of ice sheet contribution to sea-level. (2021). doi:10.5194/tc-2021-175

7. DeConto, R. M. et al. The Paris Climate Agreement and future sea-level rise from Antarctica. Nature 593, 83-89 (2021).

8. Joughin, I., Shapero, D., Smith, B., Dutrieux, P. \& Barham, M. Ice-shelf retreat drives recent Pine Island Glacier Speedup. Science Advances 7, (2021).

9. Hansen, J. et al. Ice melt, sea level rise and superstorms: Evidence from paleoclimate data, climate modeling, and modern observations that $2^{\circ} \mathrm{C}$ global warming could be dangerous. Atmospheric Chemistry and Physics 16, 3761-3812 (2016). 
10. Choi, Y., Morlighem, M., Rignot, E. \& Wood, M. Ice Dynamics will remain a primary driver of Greenland ice sheet mass loss over the next century. Communications Earth \& Environment 2, (2021).

11. Pattyn, F. \& Morlighem, M. The uncertain future of the Antarctic Ice Sheet. Science $\mathbf{3 6 7 , 1 3 3 1 - 1 3 3 5}$ (2020).

12. Clark, P. U. et al. Consequences of twenty-first-century policy for multi-millennial climate and sea-level change. Nature Climate Change 6, 360-369 (2016).

13. Day, J. W., Gunn, J. D. \& Burger, J. R. Diminishing opportunities for sustainability of coastal cities in the anthropocene: A Review. Frontiers in Environmental Science 9, (2021).

14. Nicholls, R. J. et al. Integrating new sea-level scenarios into coastal risk and adaptation assessments: An ongoing process. WIREs Climate Change 12, (2021).

15. Milne, G. A., Gehrels, W. R., Hughes, C. W. \& Tamisiea, M. E. Identifying the causes of sea-level change. Nature Geoscience 2, 471-478 (2009).

16. Stammer, D., Cazenave, A., Ponte, R. M. \& Tamisiea, M. E. Causes for contemporary regional sea level changes. Annual Review of Marine Science 5, 21-46 (2013).

17. Kopp, R. E. et al. Probabilistic 21st and 22nd Century Sea-level projections at a global network of tide-gauge sites. Earth's Future 2, 383-406 (2014).

18. Slangen, A. B. et al. A review of recent updates of sea-level projections at global and Regional Scales. Surveys in Geophysics 38, 385-406 (2016).

19. Katsman, C. A. et al. Exploring high-end scenarios for local sea level rise to develop flood protection strategies for a low-lying Delta-the Netherlands as an example. Climatic Change 109, 617-645 (2011).

20. Stocker, T. F. et al. Climate change 2013: The physical science basis. Contrib. Work. Group Fifth Assess. Rep. Intergov. Panel Clim. Change, (2013)

21. Adhikari, S., Ivins, E. R., Frederikse, T., Landerer, F. W. \& Caron, L. Sea-level fingerprints emergent from Grace Mission Data. Earth System Science Data 11, 629-646 (2019).

22. Tebaldi, C. et al. Extreme sea levels at different global warming levels. Nature Climate Change 11, 746-751 (2021).

23. Sweet, W. V., et al. Global and Regional Sea Level Rise Scenarios for the United States. NOAA Technical Report NOS CO-OPS 083 (2017).

24. Thompson, P. R., Widlansky, M. J., Merrifield, M. A., Becker, J. M. \& Marra, J. J. A Statistical Model for Frequency of Coastal Flooding In Honolulu, Hawaii, During the 21st Century. Journal of Geophysical Research: Oceans 124, 2787-2802 (2019).

25. Thompson, P. R. et al. Rapid increases and extreme months in projections of United States high-tide flooding. Nature Climate Change 11, 584-590 (2021). 
26. Firing, Y. L. Extreme sea level events at Hawaii: Influence of Mesoscale Eddies. Geophysical Research Letters 31, (2004).

27. Guiles, M. et al. Forecasts of wave-induced coastal hazards in the United States Pacific Islands: Past, present, and the future. Frontiers in Marine Science 6, (2019).

28. Anderson, T. R., Fletcher, C. H., Barbee, M. M., Frazer, L. N. \& Romine, B. M. Doubling of coastal erosion under rising sea level by mid-century in Hawaii. Natural Hazards 78, 75-103 (2015).

29. Habel, S., Fletcher, C. H., Rotzoll, K., El-Kadi, A. I. \& Oki, D. S. Comparison of a simple hydrostatic and a data-intensive 3D numerical modeling method of simulating sea-level rise induced groundwater inundation for Honolulu, Hawai'i, USA. Environmental Research Communications 1, 041005 (2019).

30. Habel, S., Fletcher, C. H., Anderson, T. R. \& Thompson, P. R. Sea-level rise induced multi-mechanism flooding and contribution to urban infrastructure failure. Scientific Reports 10, (2020).

31. Cooper, H. M., Fletcher, C. H., Chen, Q. \& Barbee, M. M. Sea-level rise vulnerability mapping for adaptation decisions using LIDAR DEMS. Progress in Physical Geography: Earth and Environment 37, 745-766 (2013).

32. Anderson, T. R. et al. Modeling multiple sea level rise stresses reveals up to twice the land at risk compared to strictly passive flooding methods. Scientific Reports 8, (2018).

33. Habel, S., Fletcher, C. H., Rotzoll, K. \& El-Kadi, A. I. Development of a model to simulate groundwater inundation induced by sea-level rise and high tides in Honolulu, Hawaii. Water Research 114, 122134 (2017).

34. Bates, P. D. \& De Roo, A. P. J. A simple raster-based model for flood inundation simulation. Journal of Hydrology 236, 54-77 (2000).

35. Gallien, T. W., Schubert, J. E. \& Sanders, B. F. Predicting tidal flooding of urbanized embayments: A modeling framework and Data Requirements. Coastal Engineering 58, 567-577 (2011).

36. Paprotny, D., Morales-Nápoles, O., Vousdoukas, M. I., Jonkman, S. N. \& Nikulin, G. Accuracy of paneuropean coastal flood mapping. Journal of Flood Risk Management 12, (2018).

37. Gesch, D. B. Consideration of vertical uncertainty in elevation-based sea-level rise assessments: Mobile Bay, alabama case study. Journal of Coastal Research 63, 197-210 (2013).

38. National Oceanic and Atmospheric Administration (NOAA). NOAA/nos vertical datums transformation. National Oceanic and Atmospheric Administration (2016). Available at: http://vdatum.noaa.gov/docs/est_uncertainties.html

39. Hess, K. W., Schmalz, R. A., Zervas, C. E. \& Collier, W. Tidal Constituent And Residual Interpolation (TCARI) : a new method for the tidal correction of bathymetric data (2004).

40. Moore, A. M. et al. The Regional Ocean Modeling System (roms) 4-dimensional variational data assimilation systems. Progress in Oceanography 91, 34-49 (2011).

41. Powell, B. S. Regional Ocean Modeling System (ROMS): Main Hawaiian Islands: Reanalysis. Pacific Islands Ocean Observing System (2018). Available at, http://pacioos.org/metadata/roms_hiig_reanalysis.html (Accessed: 2021) 
42. Fletcher, C. H., Mullane, R. A. \& Richmond, B. M. Beach Loss along Armored Shorelines on Oahu, Hawaiian Islands. Journal of Coastal Research 13, 209-215 (1997).

43. Habel, S. L., Fletcher, C. H., Rotzoll, K. \& El-Kadi, A. Comparison of bathtub modeling with simulation of sea level rise induced groundwater inundation. Geological Society of America Abstracts with Programs (2017). doi:10.1130/abs/2017am-301860

44. Caldwell, P. C., Merrifield, M. A. \& Thompson P. R., Sea level measured by tide gauges from global oceans - the Joint Archive for Sea Level holdings (NCEl Accession 0019568), NOAA National Centers for Environmental Information 5.5, Dataset, (2015). doi:10.7289/V5V40S7W Available at, http://uhslc.soest.hawaii.edu/data/?rq (Accessed: 2021)

45. Hooper, E., Chapman, L. \& Quinn, A. Investigating the impact of precipitation on vehicle speeds on UK motorways. Meteorological Applications 21, 194-201 (2014).

46. Mastrandrea, M.D., et al. Guidance note for lead authors of the IPCC Fifth Assessment Report on consistent treatment of uncertainties. Intergov. Panel Clim. Change, (2010).

47. National Oceanic and Atmospheric Administration (NOAA). New mapping tool and techniques for visualizing sea level rise and coastal flooding impacts. NOAA Coastal Services Center Technical Report, (2011).

48. Pregnolato, M., Ford, A., Wilkinson, S. M. \& Dawson, R. J. The impact of flooding on road transport: A depth-disruption function. Transportation Research Part D: Transport and Environment 55, 67-81 (2017).

\section{Figures}




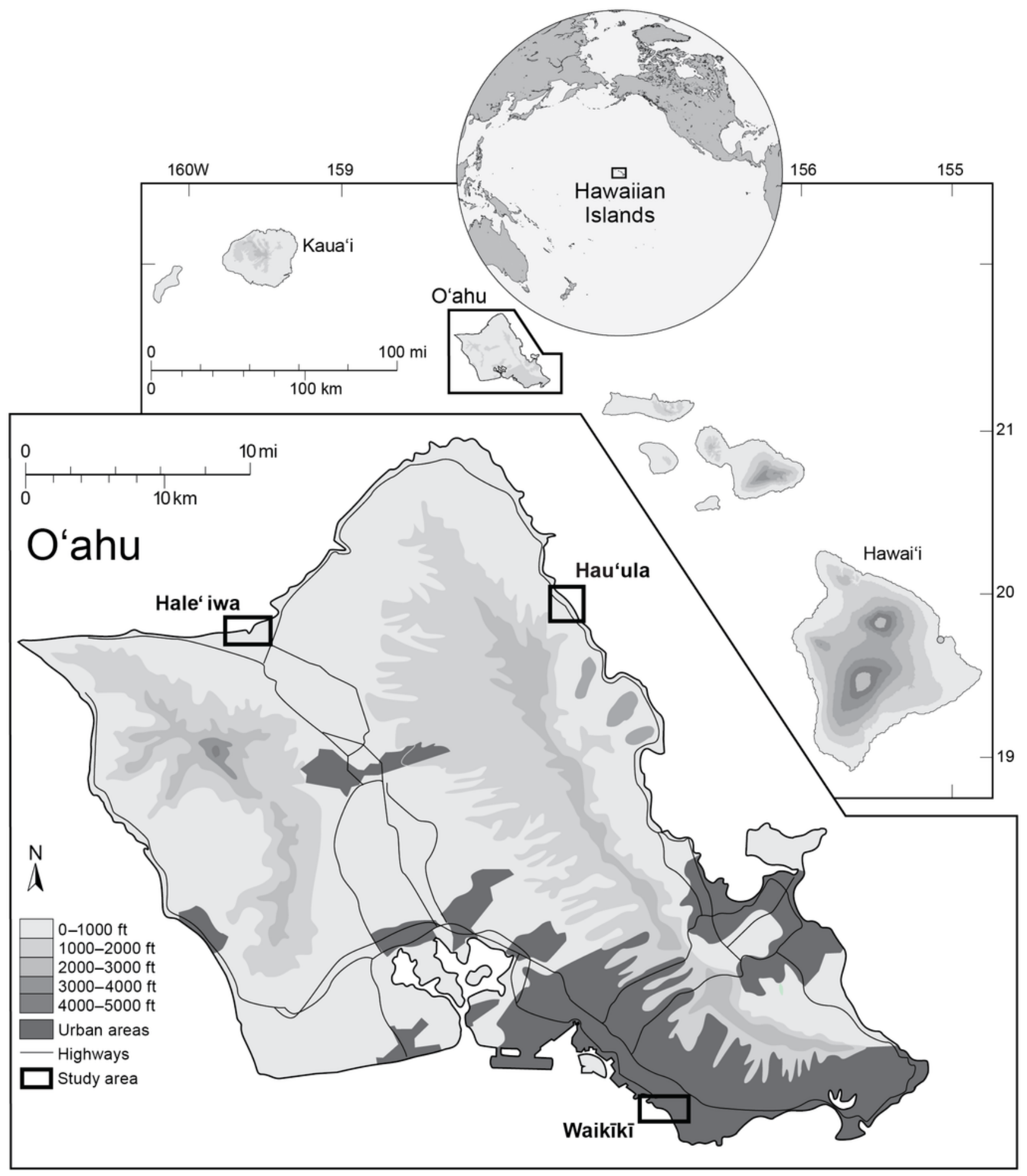

\section{Figure 1}

Location of study areas on the island of O囚ahu, Hawaiði. Modified from: Fletcher, Mullane and Richmond ${ }^{42}$. Reproduced with permission from the Coastal Education and Research Foundation, Inc. 

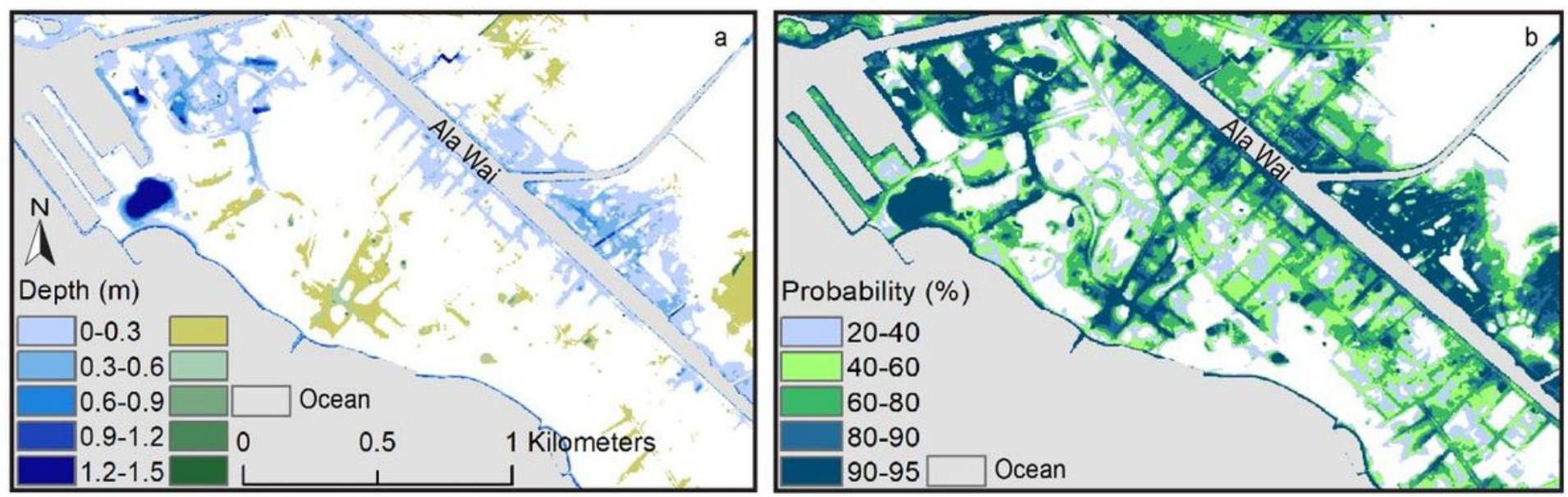

Figure 2

Location of study areas on the island of O囚ahu, Hawai囚i. Modified from: Fletcher, Mullane and Richmond ${ }^{42}$. Reproduced with permission from the Coastal Education and Research Foundation, Inc.
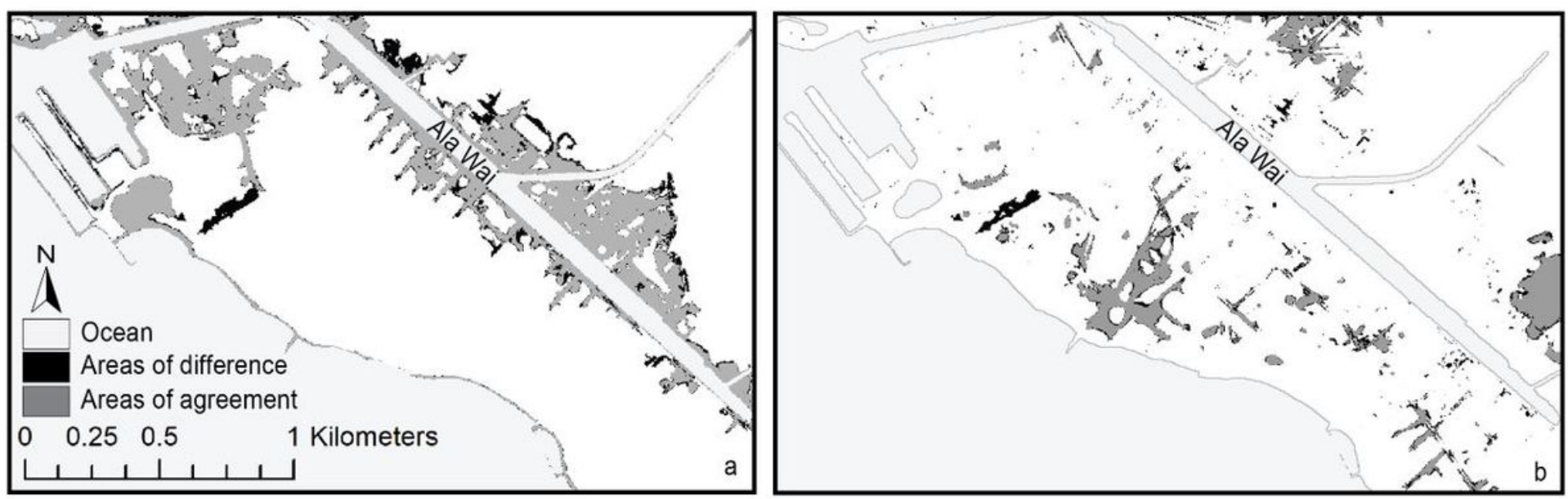

Figure 3

Waikīkī, RSLR flooding by 2100 (Intermediate scenario, $1.19 \mathrm{~m}$ ) as projected using TCARI and ROMS methods. A) Hydrologically connected, B) Topographically isolated; black - area of difference, gray - area of agreement. 


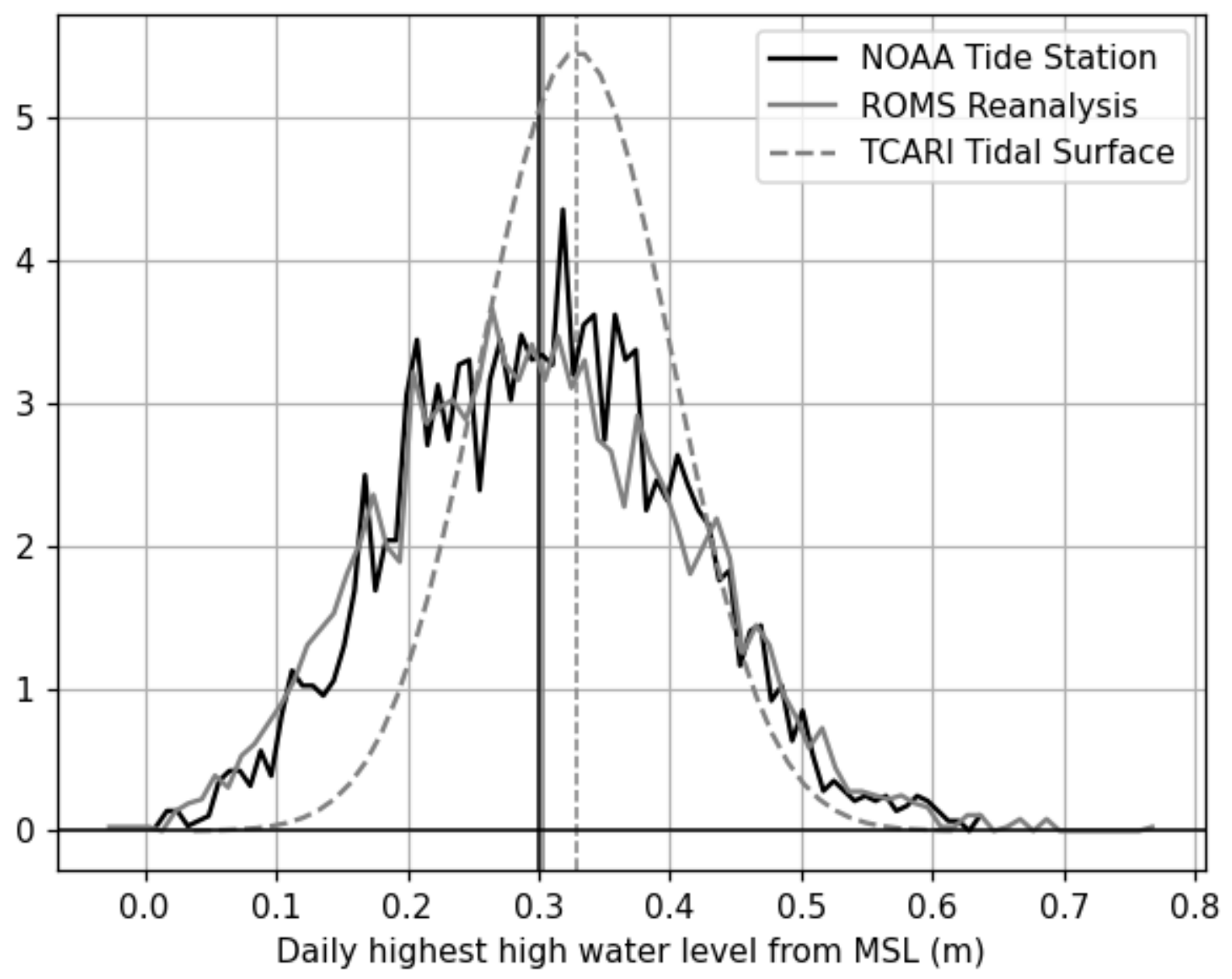

Figure 4

Probability density functions of daily highest high-water variability as obtained from the NOAA tide station in Honolulu Harbor, the ROMS Reanalysis, and a normal distribution of the mean of daily higher high water from the TCARI tidal surface. Vertical lines correspond to the mean of the respective distributions. 

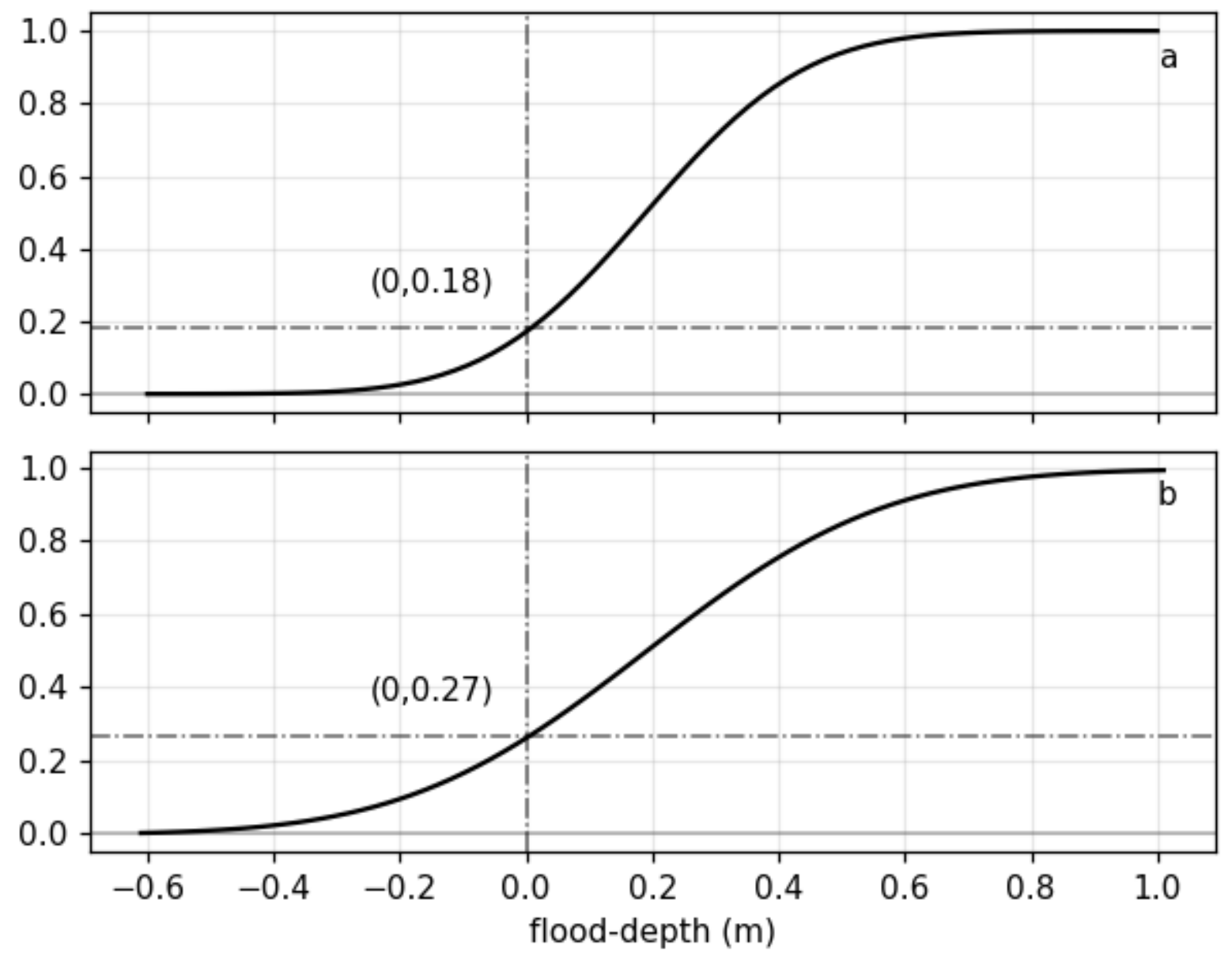

Figure 5

Comparison of two CDFs with the same mean but different flood depth spread. The figure illustrates how a broader spread results in a lower probability for corresponding flood depths. 